\title{
Avaliação de Fungicidas para o Controle de Colletotrichum gloeosporioides em Cebola
}

\author{
Fernando Haddad, Luiz A. Maffia \& Eduardo S. G. Mizubuti \\ Departamento de Fitopatologia, Universidade Federal de Viçosa, CEP 36570-000, Viçosa, MG, e-mail: lamaffia@ ufv.br
}

(Aceito para publicação em 12/05/2003)

Autor para correspondência: Luiz A. Maffia

HADDAD, F., MAFFIA, L.A. \& MIZUBUTI, E.S.G. Avaliação de fungicidas para o controle de Colletotrichum gloeosporioides em cebola. Fitopatologia Brasileira 28:435-437. 2003.

\section{RESUMO}

A antracnose foliar causada por Colletotrichum gloeosporioides é a doença mais importante da cebolicultura (Allium cepae) em Guidoval e Guiricema, MG. Para controle da doença, utilizam-se intensivamente fungicidas, principalmente benomil (Ben), o que tem sido pouco efetivo. Neste trabalho, testou-se a hipótese da existência de isolados de C. gloeosporioides resistentes ao Ben e se comparou a eficiência de diferentes fungicidas no controle do patógeno. Nas concentrações testadas, Ben impediu o crescimento micelial do fungo, e a germinação de conídios decresceu com o aumento da concentração do produto. Independente do isolado do patógeno e da concentração dos fungicidas, ocorreu maior inibição da germinação com Tiofanato metílico (Tm) + Mancozeb (Man), Man, Clorotalonil (Clo), Ben+Man, TM+Clo, Captan (Cap) e
Procloraz (Pro). Excetuando-se Clo, os demais tratamentos inibiram totalmente o crescimento micelial do fungo. Em casa de vegetação, pulverizaram-se os diferentes tratamentos em plantas de cebola 'Texas Early Grano 502' (TEG502) e 24 h após inoculou-se o patógeno. Maior redução na intensidade da doença ocorreu com TM+Man, TM+Clo, Ben+Man, Man, Cap, Clo, Ben e Pro. Em plantas de TEG502, pulverizaram-se diferentes fungicidas imediatamente após, dois, quatro ou seis dias após inoculação do patógeno. Na pulverização imediatamente após a inoculação, Ben e Pro foram os mais eficientes; nas demais épocas, nenhum fungicida reduziu a severidade da doença.

Palavras-chave adicionais: controle químico, manejo, Allium cepa.

\section{ABSTRACT}

Evaluation of fungicides to control Colletotrichum gloeosporioides on onion

Foliar anthracnose caused by Colletotrichum gloeosporioides is the most important onion (Allium cepae) disease in Guiricema and Guidoval-MG. Fungicides, mostly benomyl (Ben), are intensively sprayed for disease control but they have been inefficient. We tested the hypothesis of occurrence of resistant isolates of $C$. gloeosporioides to Ben and compared fungicides for pathogen control. Conidial germination of the isolates decreased as Ben concentration increased and the fungicide completely prevented mycelial growth. For all pathogen isolates tested, disregarding fungicide concentration, methyl thyophanate (MT) + mancozeb
(Man), Man, chlorothalonil (Chl), Ben+Man, TM+Clo, captan (Cap), and prochloraz (Pro) inhibited germination. All fungicide treatments but Chl, completely halted mycelial growth. Under greenhouse conditions each treatment was sprayed on onion 'Texas Early Grano 502' (TEG502) plants and the fungus was inoculated $24 \mathrm{~h}$ later. The most efficient treatments in reducing disease intensity were MT+Man, MT+Chl, Ben+Man, Man, Cap, Chl, Ben, and Pro. Ben, TM, Pro or Car was sprayed immediately after, or two, four, or six days after pathogen inoculation in plants of TEG502. Ben and Pro were the most efficient when sprayed right after inoculation; no fungicide controlled the disease at the other spray times.
A cebola (Allium cepae L.), cultivada em praticamente todo o mundo, detém o terceiro lugar entre as hortaliças de maior expressão econômica no Brasil. Uma das doenças mais importantes da cultura é a antracnose foliar, causada pelo fungo Colletotrichum gloeosporioides (Penz.) Penz. et Sacc. (Sensu Arx, 1957). Esta doença, também conhecida como mal-das-setevoltas, foi inicialmente constatada causando severas perdas em 1940, no Estado do Rio Grande do Sul (Saturnino \& Jaccoud Filho, 1980). Atualmente, é um dos fatores limitantes à cebolicultura no Nordeste brasileiro (Assunção, 1997), em Santa Catarina (Boff, 1996) e na região de Guidoval e Guiricema, MG.

Como há baixa disponibilidade de cultivares resistentes, a principal estratégia de manejo da doença é o controle químico, no qual usa-se principalmente o benomil (Ben), isoladamente ou associado a fungicidas protetores (Abreu, 1990). A eficiência de Ben + mancozeb (Man), Ben + captan (Cap) e prochloraz (Pro) no controle da doença já foi relatada (Maranhão et al., 1991, 1994, 1996, 1997 e 1998). Na região de Guidoval e Guiricema, utiliza-se o Ben intensivamente, sem controle efetivo da antracnose. É conhecida a resistência de fungos aos fungicidas benzimidazoles, especificamente ao Ben (Keinath \& Zitter, 1998), a qual já foi, também, observada em Colletotrichum spp. (Bernstein et al., 1995; Freeman et al., 1997; Norman \& Strandberg, 1997). Face ao exposto, levantou-se a hipótese de estar ocorrendo resistência de C. gloeosporioides a Ben, em vista da baixa eficiência do fungicida, amplamente usado na região de Guidoval e Guiricema. Neste trabalho, avaliou-se a resistência de diferentes isolados de C. gloeosporioides ao 
Ben e, paralelamente, testou-se a eficiência de fungicidas no controle do patógeno, em condições de laboratório e de casa de vegetação.

Para avaliar a inibição de germinação de conídios de $C$. gloeosporioides, suspensões de $2 \times 10^{6}$ conídios/ml de 16 isolados do fungo foram misturadas ao fungicida Ben, atingindo-se concentrações finais de 1, 5, 10, 50, 100 e 1.000 $\mathrm{mg}$ de Ben/l de água destilada. Uma gota $(10 \mu \mathrm{l})$ de cada mistura foi depositada em placas de petri (uma placa = uma repetição) contendo ágar-água a $1,5 \%$. Após $18 \mathrm{~h}$ de incubação a $25^{\circ} \mathrm{C}$ no escuro, estimou-se a percentagem de conídios germinados (tubos germinativos de comprimento igual ou superior ao dos conídios). Apesar de a resposta variar entre os isolados, para todos a germinação decresceu com o aumento da concentração do fungicida. Misturou-se uma suspensão de conídios de três isolados do patógeno aos fungicidas Cap, Ben, Man, Ben+Man, tiofanato metílico (Tm), clorotalonil (Clo), Tm+Clo, Tm+Man, Pro ou carbendazim (Car), em três dosagens: a recomendada, $20 \%$ acima e $20 \%$ abaixo (dose recomendada: $\mathrm{Cap}=1,2 ; \mathrm{Ben}=1,0$; Man=2,4; Tm=0,49; Clo=1,5; Car=0,5 g de p.a./l de água e Pro=0,675 ml de p.a./l de água). Após $18 \mathrm{~h}$ de incubação, a 25 ${ }^{\circ} \mathrm{C}$ no escuro, o percentual de conídios germinados, independente da concentração e do isolado, foi menor com os fungicidas Tm+Man, Man, Clo, Ben+Man, Tm+Clo e Cap (Figura 1).

Para estudar a inibição de crescimento micelial de $C$. gloeosporioides, discos de meio de cultura com micélio (5 mm de diâmetro) de cada um de 20 isolados foram colocados em placa de petri, contendo $20 \mathrm{ml}$ de meio de cultura + Ben, nas concentrações anteriores. Após incubação, a $25^{\circ} \mathrm{C}$ no escuro, e a intervalos de dois dias, mensurou-se o diâmetro da colônia em duas direções perpendiculares em cada placa, até que o micélio das colônias da testemunha atingisse os bordos da placa. Todas as concentrações de Ben inibiram o crescimento micelial de todos os isolados do patógeno. De três isolados do fungo, depositaram-se discos em placa de petri contendo 20

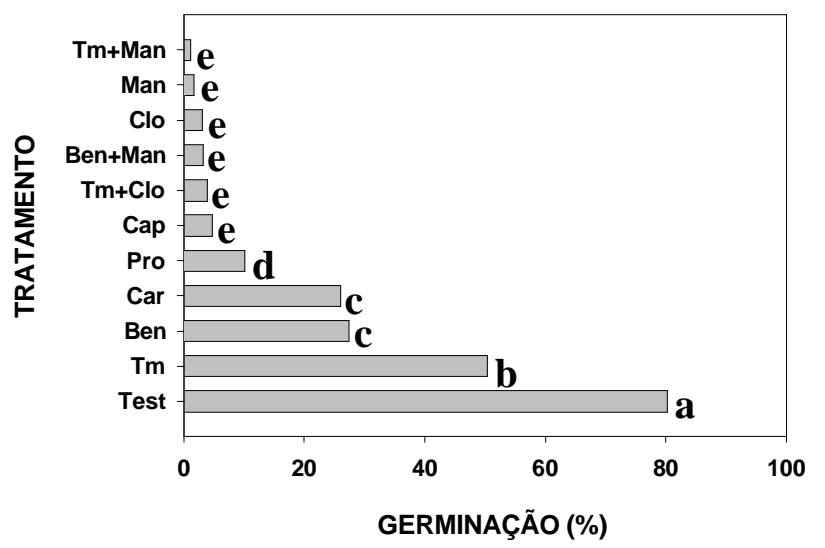

FIG. 1 - Germinação de conídios de Colletotrichum gloeosporioides nos tratamentos: Testemunha (Test); tiofanato metílico (Tm); carbendazim (Car); procloraz (Pro); benomyl (Ben); clorotalonil (Clo); captan (Cap); mancozeb (Man). Colunas seguidas pela mesma letra não diferem significativamente entre si pelo teste de Tukey $(P=0,05)$. $\mathrm{ml}$ de meio de cultura + fungicida/mistura, nas concentrações já descritas. O restante do procedimento foi como acima descrito. Excetuando-se o Clo, os demais fungicidas, em todas as concentrações, inibiram o crescimento micelial de todos os isolados.

Em testes em casa de vegetação, pulverizaram-se os fungicidas (dose recomendada) em plantas de 'Texas Early Grano 502' (TEG502), com 60 dias. Após 24 h, atomizou-se, por planta, uma suspensão de 1 x $10^{5}$ conídios/ml. Após permanecerem por $24 \mathrm{~h}$ em câmara de nevoeiro, as plantas foram transferidas para casa de vegetação. Após a incubação, e a intervalos de dois dias, avaliaram-se a severidade e a incidência da doença e se estimou a área abaixo da curva de progresso da doença (AACPD). A menor AACPD estimada foi com os fungicidas Tm+Man, Tm+Clo, Ben+Man, Man, Cap, Clo, Ben e Pro (Figura 2).

Avaliou-se o efeito de Ben, Tm, Pro ou Car na severidade da doença em casa de vegetação, onde plantas de 40 dias foram inoculadas com uma suspensão de $1 \times 10^{5}$ conídios/ml e, após permanecerem por $24 \mathrm{~h}$ em câmara de nevoeiro, pulverizou-se cada fungicida em quatro épocas:

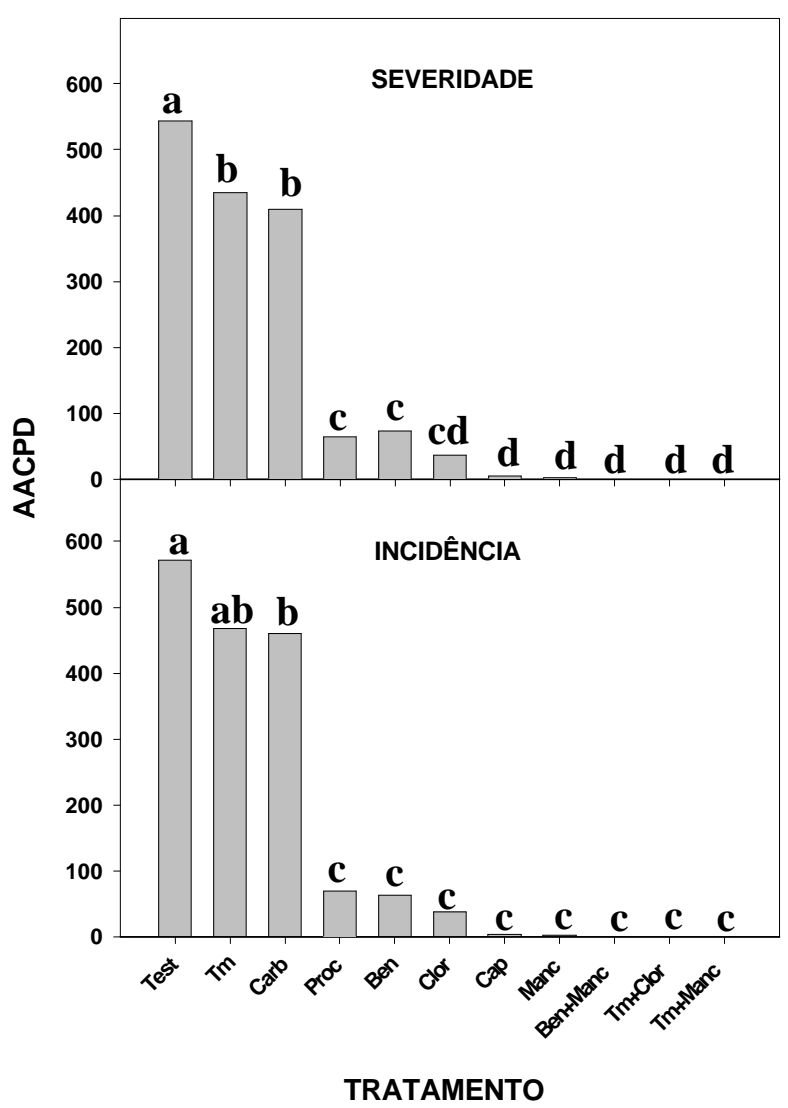

FIG. 2 - Área abaixo da curva de progresso da antracnose da cebola (Allium cepae) (AACPD), em condições de casa de vegetação estimada nos tratamentos: Testemunha (Test); tiofanato metílico (Tm); carbendazim (Car); procloraz (Pro); benomil (Ben); clorotalonil (Clo); captan (Cap); mancozeb (Man). Colunas seguidas pela mesma letra não diferem significativamente entre si pelo teste de Tukey $(P=0,05)$. 
TABELA 1- Área abaixo da curva de progresso da antracnose da cebola (Allium cepae) (AACPD), em casa de vegetação, após pulverização de fungicidas, imediatamente após (PIA) ou aos dois, quatro ou seis dias da inoculação de Colletotrichum gloeosporioides

\begin{tabular}{lrrrrc}
\hline \hline \multirow{2}{*}{ TRATAM ENTO } & \multicolumn{4}{c}{ AACPD (dias x severidade) } \\
\cline { 2 - 6 } & \multicolumn{1}{c}{ PIA } & 2 dias & 4 dias & 6 dias \\
\hline Testemunha com inoculação & $246,07 \mathrm{a}^{*}$ & $246,07 \mathrm{a}$ & $246,07 \mathrm{a}$ & $246,07 \mathrm{a}$ \\
Carbendazim & $229,13 \mathrm{ab}$ & $221,77 \mathrm{a}$ & $221,25 \mathrm{a}$ & $227,23 \mathrm{a}$ \\
Tiofanato Metilico & 217,48 & $\mathrm{~b}$ & $220,95 \mathrm{a}$ & $221,02 \mathrm{a}$ & $226,53 \mathrm{a}$ \\
Benomil & 6,33 & $\mathrm{c}$ & $221,55 \mathrm{a}$ & $224,68 \mathrm{a}$ & $226,19 \mathrm{a}$ \\
Procloraz & 3,51 & $\mathrm{c}$ & $216,19 \mathrm{a}$ & 218,79 a & $224,50 \mathrm{a}$ \\
\hline
\end{tabular}

*Em cada coluna, os valores seguidos pela mesma letra não diferem significativamente entre si pelo teste de Tukey $(\mathrm{P}=0,05)$.

imediatamente após, dois, quatro ou seis dias após a inoculação. Após a incubação, e diariamente durante cinco dias, avaliou-se a severidade da doença. Obteve-se menor AACPD estimada com Ben e Pro, pulverizados imediatamente após a inoculação. Nas demais épocas, nenhum fungicida foi eficiente (Tabela 1).

Em vista dos resultados obtidos, não se detectou resistência dos isolados de C. gloeosporioides ao benomil, o que indica que, provavelmente, no campo, o fungicida esteja sendo aplicado em épocas e, ou, intervalos inadequados. Pelos resultados obtidos em condições ambientais favoráveis, sugere-se que os fungicidas devam ser aplicados preventivamente, pois a eficiência de fungicidas sistêmicos decresce, quando pulverizados a partir do segundo dia após a inoculação. Fungicidas protetores poderão ser eficientes no controle da doença, se aplicados em épocas e intervalos adequados. A eliminação dos restos culturais infestados é importante (Moreira, 2000) e pode contribuir para reduzir a aplicação de fungicidas, racionalizando o manejo da doença e diminuindo o impacto no agroecossistema.

\section{REFERÊNCIAS BIBLIOGRÁFICAS}

ABREU, C.L.N. Reação de cultivares de cebola do ciclo de dias longos ao Mal-das-sete-voltas. Summa Phytopathologica 16:237-242. 1990. ASSUNÇÃO, I.P. Identificação de fontes de resistência em cultivares de cebola (Allium cepa L.) e análise da variabilidade de Colletotrichum gloeosporioides (Pen) Penz. Et Sacc. (Sensu Arx, 1957) assistida por marcadores moleculares. (Tese de Mestrado). Pernambuco. Universidade Federal de Pernambuco. 1997.
BERNSTEIN, B., ZEHHR, E.I., DEAN, R.A. \& SHABI, E. Characteristics of Colletotrichum from peach, apple, pecan, and other hosts. Plant Disease 79:478-482. 1995.

BOFF, P. Levantamento de doenças na cultura da cebola em Santa Catarina. Fitopatologia Brasileira 21:110-114. 1996.

FREEMAN, S., NIZANI, Y., DOTAN, S., EVEN, S. \& SANDO, T. Control of Colletotrichum acutatum in strawberry under laboratory, greenhouse, and field conditions. Plant Disease 81:749-752. 1997.

KEINATH, A.P. \& ZITTER, T.A. Resistance to benomyl and thiophanate-methyl in Didymella bryoniae from South Carolina and New York. Plant Disease 82:479-484. 1998.

MALOY, O.C. Plant disease control: principles and practice. New York: John Wiley \& Sons. 1993.

MARANHÃO, E.H. DE A., CANDEIA, J.A., WANDERLEY, L.J. DA G. \& MARANHÃO, E.A. DE A. Controle químico do "mal-desete-voltas" em cebola, causado por Colletotrichum gloeosporioides Pens, no estado de Pernambuco. Horticultura Brasileira 9:45. 1991 (Resumo).

MARANHÃO, E.H. DE A., CANDEIA, J.A., MARANHÃO, E.A. DE A., WANDERLEY, L.J. DA G. \& LYRA FILHO, H.P. Avaliação e intervalo de aplicação de fungicidas no controle do "mal-de-setevoltas" em cebola. Horticultura Brasileira 12:88. 1994 (Resumo).

MARANHÃO, E.H. DE A., CAVALCANTE, V.A., CANDEIA, J.A., MARANHÃO, E.A. DE A. \& LYRA FILHO, H.P. Avaliação de fungicidas no controle do "mal-de-sete-voltas" em cebola causado por Colletotrichum gloeosporioides Pens, para o estado de Pernambuco. Horticultura Brasileira 14:96. 1996. (Resumo).

MARANHÃO, E.H. DE A., CAVALCANTE, V.A.L.B., CANDEIA, J.A., MARANHÃO, E.A. DE A., LYRA FILHO, H.P. \& RODRIGUES, V.J.L.B. Avaliação do controle químico do "mal-desete-voltas" em cebola, causado pelo fungo Colletotrichum gloeosporioides Pens, no estado de Pernambuco. Horticultura Brasileira 15:230. 1997. (Resumo).

MARANHÃO, E.H. DE A., MARANHÃO, E.A. DE A., LYRA FILHO, H.P. \& RODRIGUES, V.J.L.B. Estudo da eficiência do fungicida Captan no controle do fungo Colletotrichum gloeosporioides Pens., em cebola. Horticultura Brasileira 16:175. 1998. (Resumo).

MOREIRA, A.J.A. Epidemiologia da antracnose foliar da cebola, causada por Colletotrichum gloeosporioides. (Tese de Mestrado). Viçosa. Universidade Federal de Viçosa. 2000.

NORMAN, D.J., \& STRANDBERG, J.O. Survival of Colletotrichum acutatum in soil and plant debris of leatherleaf fern. Plant Disease 81:1177-1180. 1997.

SATURNINO, H.M. \& JACCOUD FILHO, C. da. Doenças da cebola. Informe Agropecuário 6:47-77. 1980. 